\title{
T-cell activation by treatment of cancer patients with EMD 521873 (Selectikine), an IL-2/anti-DNA fusion protein
}

\author{
Julien Laurent ${ }^{1,3^{*}}$, Cedric Touvrey ${ }^{1,8}$, Silke Gillessen ${ }^{2}$, Magali Joffraud ${ }^{1}$, Manuela Vicari ${ }^{1}$, Caroline Bertrand ${ }^{1}$, \\ Stefano Ongarello ${ }^{3}$, Bernd Liedert ${ }^{3}$, Elisa Gallerani ${ }^{4}$, Joachim Beck ${ }^{5}$, Aurelius Omlin ${ }^{2}$, Cristiana Sessa ${ }^{4}$, \\ Sonia Quaratino ${ }^{3}$, Roger Stupp ${ }^{6}$, Ulrike S Gnad-Vogt ${ }^{3,9}$ and Daniel E Speiser ${ }^{7}$
}

\begin{abstract}
Background: EMD 521873 (Selectikine or NHS-IL2LT) is a fusion protein consisting of modified human IL-2 which binds specifically to the high-affinity IL-2 receptor, and an antibody specific for both single- and double-stranded DNA, designed to facilitate the enrichment of IL-2 in tumor tissue.

Methods: An extensive analysis of pharmacodynamic (PD) markers associated with target modulation was assessed during a first-in-human phase I dose-escalation trial of Selectikine.

Results: Thirty-nine patients with metastatic or locally advanced tumors refractory to standard treatments were treated with increasing doses of Selectikine, and nine further patients received additional cyclophosphamide. PD analysis, assessed during the first two treatment cycles, revealed strong activation of both $\mathrm{CD} 4^{+}$and $\mathrm{CD} 8^{+} \mathrm{T}$-cells and only weak NK cell activation. No dose response was observed. As expected, Treg cells responded actively to Selectikine but remained at lower frequency than effector $C D 4^{+} T$-cells. Interestingly, patient survival correlated positively with both high lymphocyte counts and low levels of activated $C D 8^{+} \mathrm{T}$-cells at baseline, the latter of which was associated with enhanced T-cell responses to the treatment.
\end{abstract}

Conclusions: The results confirm the selectivity of Selectikine with predominant T-cell and low NK cell activation, supporting follow-up studies assessing the clinical efficacy of Selectikine for cancer patients.

Keywords: Interleukin-2, Fusion protein, Tumor, Lymphocytes, Cancer-testis antigen

\section{Background}

T-lymphocytes have the potential to limit tumor progression but may be impaired in their function due to lack of growth factors and/or the presence of immunosuppressive mechanisms, particularly within metastatic lesions [1-3]. Immunotherapy with recombinant human interleukin-2 (IL-2) is an attractive treatment option for certain metastatic cancers, as it exerts both stimulatory and regulatory functions on the immune system and is, along with other members of the common $\gamma$ chain $(\gamma \mathrm{c})$ cytokine family, central to immune homeostasis $[4,5]$.

\footnotetext{
* Correspondence: julien.laurent@merckgroup.com

'Division of Experimental Oncology, Multidisciplinary Oncology Center, Centre Hospitalier Universitaire Vaudois, Lausanne, Switzerland

${ }^{3}$ Global Clinical Development Unit-Oncology, Merck KGaA, Frankfurter Str. 250, D-64293, Darmstadt, Germany

Full list of author information is available at the end of the article
}

IL-2 acts via IL-2 receptors (IL-2R), consisting of either the trimeric $\alpha \beta \gamma$ receptor, or the dimeric $\beta \gamma$ receptor [6]. Both IL-2R variants transmit signaling upon IL-2 binding. However, the trimeric $\alpha \beta \gamma$ receptor has 10-100 times higher affinity for IL-2 than the dimeric form [7], because IL-2R $\alpha$ (CD25) confers high-affinity binding to IL-2. The trimeric IL-2R is mainly expressed on activated T-cells and $\mathrm{CD} 4^{+}$Treg cells (forkhead box P3 [Foxp3] positive T-cells) [7]. High-dose IL-2 is used for the treatment of patients with metastatic melanoma and metastatic renal cell carcinoma, and has a long-term impact on overall survival $[8,9]$. However, high-dose IL-2 treatment is associated with considerable toxicity, in particular vascular leak syndrome (VLS) with accumulation of extravascular fluid in organs such as the lung and liver. [10-12]. There is no treatment for VLS other than

\section{Biomed Central}


withdrawal of IL-2. Low-dose IL-2 regimens have been tested in patients to reduce side effects, at the price of reduced therapeutic results [13,14]. Many mechanisms have been proposed to explain VLS. Toxicity has been attributed to direct binding of IL-2 to endothelial cells via a motif resembling a component of bacterial toxins [15] and centered around aspartic acid residue 20 (D20); others reported a vasopermeability enhancing fragment of IL-2 extending from residues 22 to 58 that increases vascular permeability independent of IL-2 bioactivity [10], or proposed that activation of cells bearing the intermediateaffinity IL-2 receptor in the vascular compartment leads to inflammatory cytokine release by natural killer (NK) and other cells [16]. In order to target IL-2 to tumor in a way of reducing its potential toxicity, Merck KGaA (Darmstadt, Germany) developed a novel fully humanized IL-2 fusion protein, EMD521873 or NHS-IL2LT (Selectikine), for the treatment of solid tumors and B-cell non-Hodgkin lymphoma [17]. Selectikine comprises the monoclonal antibody (mAb) NHS76, which recognizes single-or double-stranded DNA often released from dying tumor cells either spontaneously or following treatment with radiation or chemotherapy $[18,19]$, and two genetically modified IL-2 molecules, with a D20T mutation aimed at eliminating the toxin motif responsible for endothelial cell binding [15]. Pre-clinical data revealed that Selectikine retained low toxicity and induced anti-tumor responses. Multiple cycles of treatment can be administered safely and with the potential for improved efficacy. Furthermore, it has been shown that the D20T mutation, in the context of a whole antibody immunocytokine, was highly selective for the high-affinity IL-2R [17]. A caveat of targeting the high-affinity receptor is the possibility of activating Treg cells. Selectikine was tested in a phase I doseescalation first-in-human study in patients with advanced solid tumors, as a 1-h intravenous (iv) infusion on 3 consecutive days every 3 weeks (group 1). Low-dose administration of cyclophosphamide at $300 \mathrm{mg} / \mathrm{m}^{2}$ one day prior to the first Selectikine infusion in each cycle was also assessed (group 2) as cyclophosphamide has been reported to suppress Treg cells and to enhance the antitumor activity of immunotherapy [20-23]. At all dose levels tested, no severe cardiovascular side-effects including severe hypotension or vascular leak syndrome, usually associated with native IL-2, were observed. Also, no objective tumor responses, but prolonged periods of disease stabilization in some patients, were observed [24]. We took the opportunity of this first-in-human phase I clinical trial to investigate immune modulatory effects induced by Selectikine. To this aim, an extensive analysis of pharmacodynamic markers was conducted during the first two treatment cycles. Here we report the results of this immune-monitoring, mainly from patients treated in group I.

\section{Materials and methods}

Study design, patient eligibility criteria and clinical data are detailed in the Additional file 1 available online, and in the recent paper by Gillessen et al. [24]. The study was performed in accordance with the guidelines of the declaration of Helsinki, the International Conference on harmonization, and regulatory authorities and the protocol was approved by local ethics committees.

\section{Blood samples}

For flow cytometry analysis, whole blood $(10 \mathrm{~mL})$ was collected in EDTA tubes (Vacutainer ${ }^{\circledR}$ Blood Collection Tubes, Becton-Dickinson [BD], Basel, Switzerland) on day 1 , before Selectikine infusion (group 1) or before cyclophosphamide administration (group 2) and on day 8 during the first two cycles of treatment, and sent to a central laboratory for direct analysis within $24 \mathrm{~h}$. During the second cycle, on days 1 and 8 for both patient groups, an additional $50 \mathrm{~mL}$ of blood was collected in LithiumHeparin tubes (Vacutainer ${ }^{\circledR}$ Blood Collection Tubes, BD) and PBMC were isolated and frozen locally for further functional analysis. Briefly, blood was diluted 50\% with PBS, overlayed onto Ficoll-Histopaque 1.077 (SigmaAldrich Chemie Gmbh, Munich, Germany) and centrifuged for $30 \mathrm{~min}$ at $400 \times \mathrm{g}$ and $20^{\circ} \mathrm{C}$. The PBMC fraction was collected, washed in PBS, counted, aliquoted, and frozen at $-80^{\circ} \mathrm{C}$ in $90 \% \mathrm{FCS} / 10 \%$ DMSO. In addition, $6 \mathrm{~mL}$ of whole blood was collected in Vacutainer SST tubes (BD) on days 1 and 3 during the first two cycles. Sera were prepared locally and frozen until analysis. Serum levels of IL-10, sIL-2R (R\&D systems, Minneapolis, USA) and neopterin (IBL, Hamburg, Germany) were measured by ELISA according to the manufacturer's instructions.

\section{Flow cytometry}

Fluorescence-activated cell sorting (FACS) analysis on fresh blood was performed on total leucocytes after lysis of erythrocytes. Briefly, cells were stained with the following mAbs: FITC-conjugated anti-Bcl2, anti-Ki67, anti-perforin; and isotype control IgG1k or IgG2b; PE-conjugated anti-CD45RA, anti-CD127; PerCPconjugated anti-CD8, anti-CD3, anti-HLA-DR, anti-CD56 and anti-CD16; PE-Cy7-conjugated antiCD25, anti-CCR7; APC-conjugated anti-CD38, antiHLA-DR, anti-granzyme B, and isotype control IgG1k; APC-H7-conjugated anti-CD4 and anti-CD3. Antibodies were purchased from BD Pharmingen, except for FITC-conjugated anti-Foxp3 which was purchased from eBiosciences, San Diego, USA. Data were acquired using a FACS LSRII flow cytometry machine (BD), and analyzed with FCSExpress version 3 software (De Novo software, Ontario, Canada). 


\section{Peptide stimulation assay}

Antigen-specific $\mathrm{CD}^{+}$T-cell responses specific for cancer-testis tumor antigens were assessed in vitro by stimulating PBMCs collected on days 1 and 8 of the second cycle of Selectikine treatment with five different HLA-A2 restricted peptides (Melan-A/ELAGIGILTV; MAGE-A3/KVAELVHFL; NY-ESO-1/SLLMWITQA; MAGEA10/GLYDGMEHL and SSX-2/KASEKIFYV). Briefly, CD8 ${ }^{+}$ T-cells $\left(1 \times 10^{5}\right)$ enriched by magnetic beads (Miltenyi Biotec, Bergisch Gladbach, Germany) were co-cultured with irradiated $\mathrm{CD}^{-}$cells (ratio of 1:1) in RPMI plus $8 \%$ $\mathrm{AB}$ human serum (Sigma-Aldrich Chemie $\mathrm{GmbH}$, Buchs, Switzerland) in 96-well plates, and stimulated with the peptides $(20 \mu \mathrm{M})$. After $48 \mathrm{~h}$, medium was supplemented with IL-2 $(150 \mathrm{U} / \mathrm{mL})$ and IL-7 $(20 \mathrm{ng} / \mathrm{m})$. On day 7 , cells were collected, stained with multimers and antibodies, and analyzed on an LSRII flow cytometer (BD). Acquired data were analyzed using FCSExpress version 3 software (De Novo software).

\section{Intracellular cytokine staining}

Intracellular cytokine staining for IFN $\gamma$ and $\mathrm{TNF} \alpha$ was performed together with labeling with tetramers and CD8-specific antibodies. $1 \times 10^{6} \mathrm{CD}^{+}$enriched T-cells (Miltenyi Biotec) were incubated for 5 hours at $37^{\circ} \mathrm{C}$ with $1 \times 10^{6}$ T2 cells pulsed with $10 \mu \mathrm{g} / \mathrm{mL}$ irrelevant HIV-1 Pol476-484 (ILKEPVHGV) peptide, or $10 \mu \mathrm{g} / \mathrm{mL}$ tumor antigenic peptides, or $1 \mu \mathrm{g} / \mathrm{mL}$ PMA $/ 0.25 \mu \mathrm{g} / \mathrm{mL}$ ionomycin. After $1 \mathrm{~h}, 10 \mu \mathrm{g} / \mathrm{mL}$ brefeldin A (SigmaAldrich Chemie GmbH, Buchs, Switzerland) was added. $4 \mathrm{~h}$ later cells were stained with multimers and antibodies, fixed, permeabilized, and incubated with antiIFN $\gamma$-FITC and anti-TNF $\alpha$-APC mAbs in PBS/0.1\% saponin for $30 \mathrm{~min}$ at $4^{\circ} \mathrm{C}$. Cells were analyzed on a LSRII flow cytometer (BD). Acquired data were analyzed using FCSExpress version 3 software (De Novo software).

\section{Treg cell inhibition test}

To test the suppressive activity of Treg cells, their ability to inhibit the proliferation of autologous $\mathrm{CD}^{+}{ }^{+} \mathrm{T}$ cells we measured in CFSE assays. Briefly, CD4 ${ }^{+} \mathrm{T}$-cells were negatively selected using magnetic beads from PBMC collected on days 1 and 8 of the second cycle of treatment. The CD25-expressing $\mathrm{CD}^{+}$fraction was then positively selected using the $\mathrm{CD} 4^{+} \mathrm{CD} 25^{+}$regulatory $\mathrm{T}$-cell isolation kit (Miltenyi Biotec) according to the manufacturer's instructions. $\mathrm{CD} 4{ }^{+} \mathrm{CD} 25^{-}$T-effector cells $\left(6 \times 10^{5}\right)$ were labeled with CFSE (final concentration $2 \mu \mathrm{M})$ and cultured in 96 well-plates, stimulated with anti-CD3 and anti-CD28 beads (Dynabeads ${ }^{\circledR}$ Human T-Activator CD3/CD28, LuBioScience GmbH, Lucerne, Switzerland). $\mathrm{CD} 4{ }^{+} \mathrm{CD} 25^{+}$non-labeled Treg cells $\left(3 \times 10^{5}\right)$ were added to the cultures (ratio of 1:2).
After 4 days, cells were collected, and stained with the apoptotic marker VIVID, and anti-CD4 and anti-CD3 mAbs. CFSE intensity was measured on a FACS LSRII (BD).

\section{Immunohistochemistry}

Tumor tissues from archival material (pretreatment) and a biopsy collected after two treatment cycles were analyzed by immunohistochemistry. Four-micrometer thick serial sections of formalin-fixed, paraffin-embedded tissue samples were prepared. Antigen retrieval carried out using microwave treatment in $0.1 \mathrm{M}$ sodium citrate, $\mathrm{pH}$ 6.0. Staining was performed with anti-CD8, anti-CD4, antiFoxp3 and anti-Ki67 mAbs. Detection was with the DAKO EnVision ${ }^{\mathrm{TM}}+$ system using diaminobenzidine (DAB) as the chromogen (DAKO, Trappes, France). Nonimmune mouse IgG was used as a negative control. In parallel, tissue samples were stained with hematoxylin/ eosin.

\section{Statistical analyses}

Values are expressed as mean $\pm 95 \%$ confidence intervals. Statistical analysis was aimed at discovering differences due to the treatment, both in time and by dose level. Leukocyte subsets were compared between day 1 and 8 of the first two cycles using repeated measurements mixed model analysis of variance (ANOVA). The F-test, $\alpha=0.05$, in the ANOVA was used to test the fixed effects, and a post-hoc test (Tukey HSD) was applied for the pairwise comparisons. Differences were considered statistically significant at ${ }^{*} P<0.05\left({ }^{* *} P \leq 0.01\right.$, $* * * 0.005)$. All analyses were performed using JMP v.8.0.2. software (SAS Institute Inc., Cary, US).

\section{Kaplan Meier survival analysis}

Survival analyses were performed from the first day of study treatment to the date of progression, or date of death, or censored at the date of last observation. Kaplan Meier (KM) analyses were performed to estimate the relationships between survival time and biomarker baseline levels. For each biomarker individually, the baseline value for every patient was categorized into LOW or $\mathrm{HIGH}$ categories according to levels that were less or equal to the 33th percentile, or greater than the 66th percentile. The analysis was performed by the Unit for Bioinformatics (Merck Serono, Geneva), using the standard model: Overall Survival Time * Censoring. A logrank test was performed to compare the two groups (LOW, HIGH). Kaplan Meier survival analysis was performed using JMP v.8.0.2. software (SAS Institute Inc., Cary, US). 


\section{Results}

\section{Clinical background}

A total of 48 patients were enrolled, 39 were treated with Selectikine alone (group 1) in a $3+3$ doseescalation design starting from $0.075 \mathrm{mg} / \mathrm{kg}$ through $0.15,0.225,0.3,0.45,0.6$ and finally $0.9 \mathrm{mg} / \mathrm{kg}$; and nine patients with Selectikine plus cyclophosphamide (group 2, dose levels $0.45 \mathrm{mg} / \mathrm{kg}$ and $0.6 \mathrm{mg} / \mathrm{kg}$ ). Skin rash at a dose of $0.9 \mathrm{mg} / \mathrm{kg}$ was the dose limiting toxicity, and the maximum tolerated dose was therefore determined as $0.6 \mathrm{mg} / \mathrm{kg}$ in group 1. The Selectikine treatment was associated with typical IL-2-like biological effects including lymphopenia followed by lymphocytosis and eosinophilia at all dose levels, while IL-2 related clinical AEs were mainly mild to moderate. The skin rash responded well to topical corticosteroids. Compared to previous studies, with intermediate to high IL-2 doses, Selectikine induced only mild hypotension and no vascular leak syndrome suggesting improved tolerability of this modified and more selective IL-2 moiety. Detailed clinical results have been reported in a recent publication [24].

In the following sections, we focus on the analysis of pharmacodynamic markers, mainly assessed during the first two treatment cycles; on day 1 before Selectikine infusion (day -1 for group 2), and on day 8 .

\section{Leukocytes}

Absolute counts of leukocyte populations in peripheral blood (clinical laboratory data), including lymphocytes, monocytes and neutrophils were measured for each cycle of treatment at the following time points: before the start of Selectikine infusion (day 1), on day 3 and day 8. Leukocytes were analyzed for the dose groups from 0.075 to $0.9 \mathrm{mg} / \mathrm{kg}$ Selectikine until treatment discontinuation. The data revealed lymphopenia at day 3 at all doses tested, followed by lymphocytosis (absolute leukocytes count) 8 days after Selectikine administration, with return to basal levels after each cycle (Figure 1, upper graph). Lymphocytes were most sensitive to Selectikine, with a systematic and steady increase between each cycle; whereas the responses of monocytes and neutrophils were less strong (Figure 1, lower graphs). Notably, no significant dose effects were observed between patients subgroups, therefore the data from the subgroups were pooled for the remaining analyses.

\section{$\mathrm{CD}^{+}$and $\mathrm{CD} 8^{+}$T-cells}

As lymphocytes responded strongly to treatment, $\mathrm{CD} 8^{+}$ and $\mathrm{CD} 4^{+}$T-cells were next analyzed during the first two treatment cycles. As expected, a statistically significant and transitory increase in absolute counts as well as in the frequency of both $\mathrm{CD}^{+}$and $\mathrm{CD} 4^{+} \mathrm{T}$-cells was observed on day 8 after Selectikine infusion (Figure 2A). Notably, there was a greater increase in $\mathrm{CD} 4^{+} \mathrm{T}$-cells on

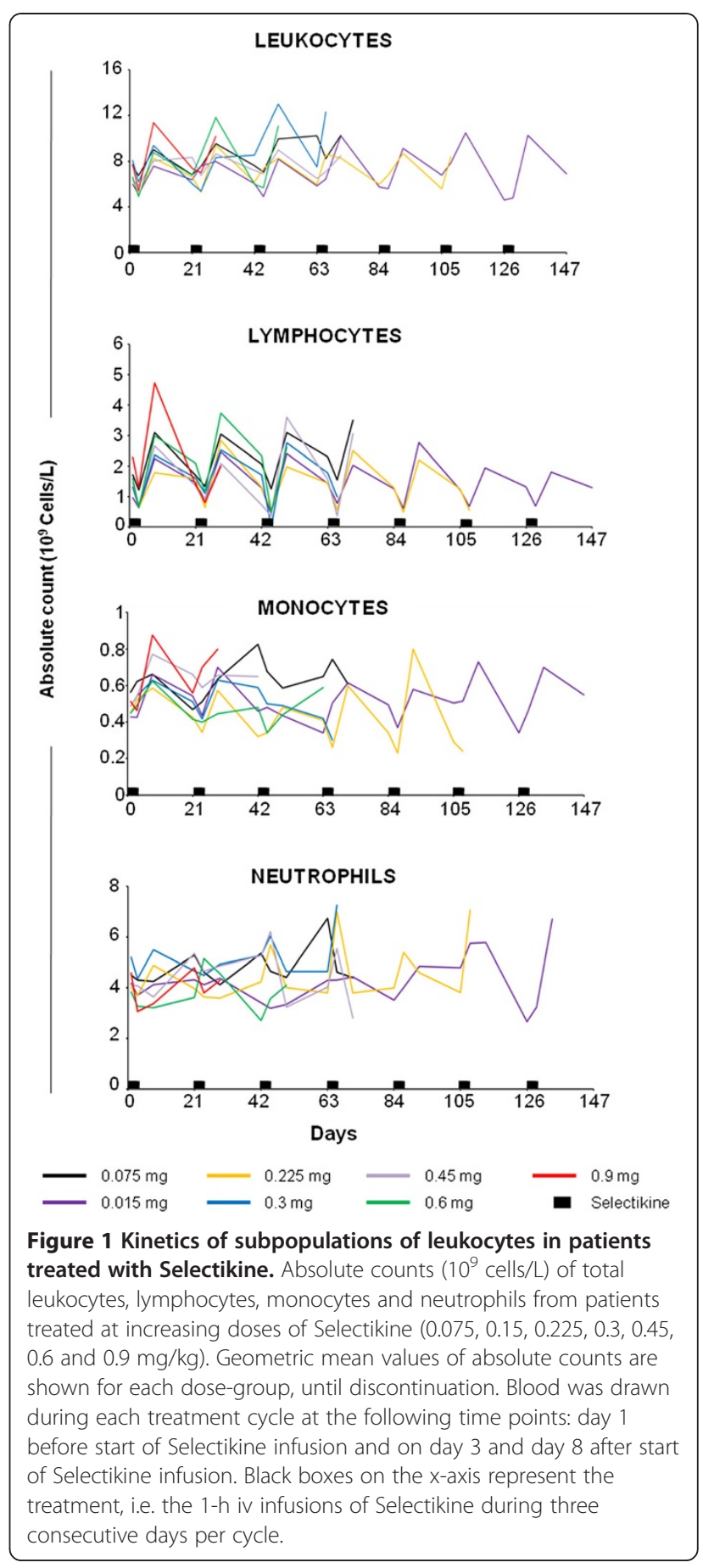

day 8 of both cycles (2.3-fold increase) compared with $\mathrm{CD}^{+} \mathrm{T}$-cells (1.5-fold increase for cycles 1 and 2), leading to a relatively small but statistically significant increase of the $\mathrm{CD} 4^{+} / \mathrm{CD}^{+}$ratio after both cycles of treatment (Figure 2B). As expected, serum concentrations of soluble IL-2R (sIL-2R) were also strongly increased shortly after Selectikine infusion (Figure 2C). The analysis of NK cells based on CD56 and CD16 surface markers showed no significant changes for both 


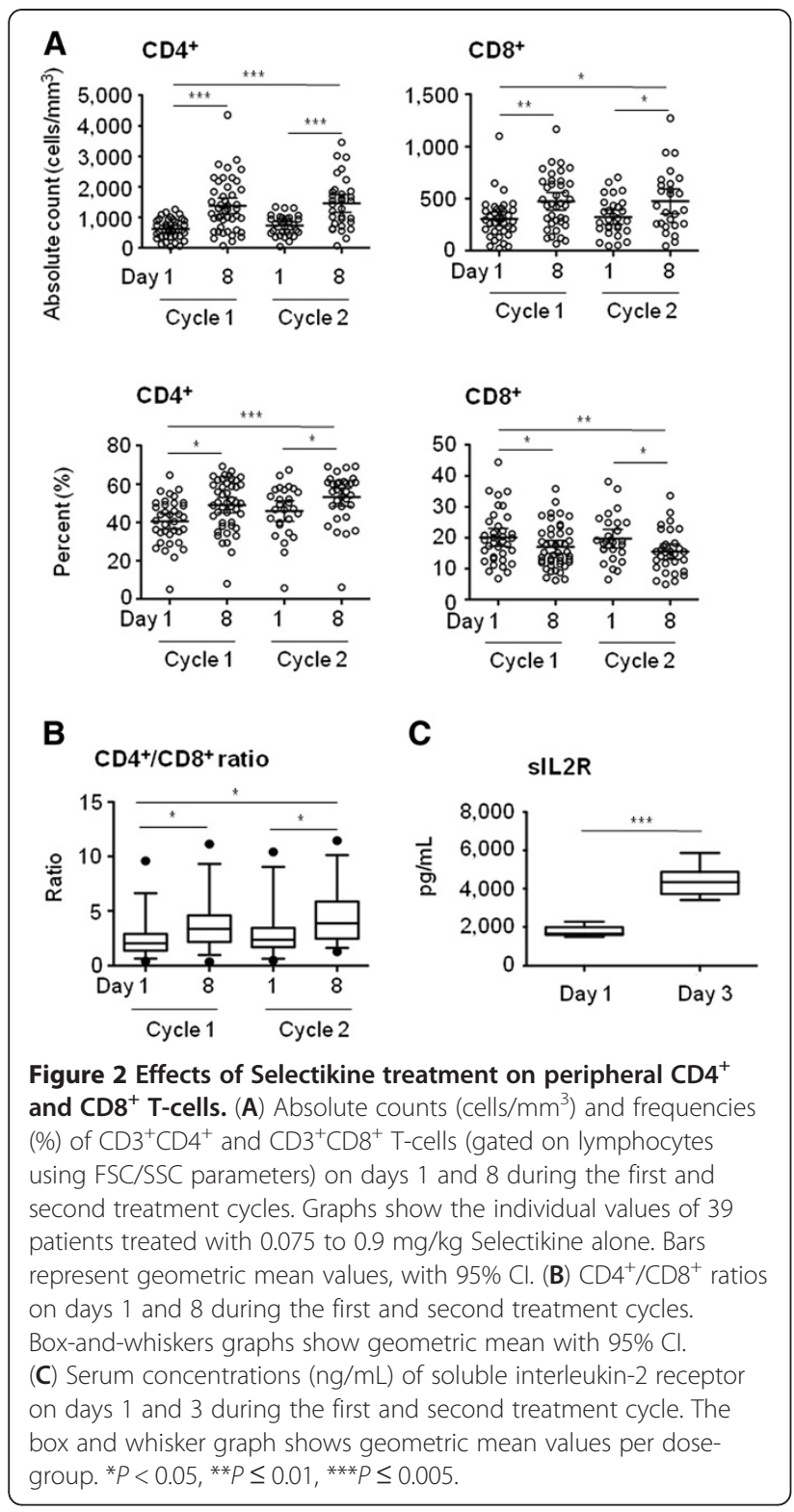

cycles monitored in terms of frequency or cytotoxicity (Additional file 1: Figure S1A and S1B), only a slight increase in absolute numbers was noted during the first cycle (Additional file 1: Figure S1A). No dose effects were observed in the analysis of NK cells.

\section{T-cell activation and proliferation}

As $\mathrm{CD}^{+}$and $\mathrm{CD}^{+}{ }^{+}$T-cells were both sensitive to Selectikine, the lymphocyte functions were next investigated. Combinations of Ki67- and HLA-DR-specific antibodies were used to analyze proliferation, and CD38- and Bcl2specific antibodies for activation [25-27]. Strong proliferation was induced in both $\mathrm{CD}^{+}$and $\mathrm{CD}^{+}$T-cells after each treatment cycle, reaching a mean of approximately $20 \%$ of proliferative $\mathrm{CD}^{+}{ }^{+}$T-cells in cycle 1
$(23.1 \% \pm 11.4)$ and $2(19.0 \% \pm 9.2)$. The proliferation of $\mathrm{CD}^{+} \mathrm{T}$-cells was similar $(22.2 \% \pm 15.8)$ in the first cycle, but less in the second cycle $(10.7 \% \pm 12.4)$ (Figure 3A). Proliferating (HLA-DR ${ }^{+} \mathrm{Ki} 67^{+}$) cells were predominantly effector memory (EM) cells, as identified by the absence of CCR7 and CD45RA expression (Figure 3A dot plot, Additional file 1: Figure S2A). Similar to the proliferation state, activated cells $\left(\mathrm{CD} 38^{+} \mathrm{Bcl}-2^{-}\right)$were also increased after both cycles for $\mathrm{CD}^{+}$and $\mathrm{CD} 8^{+}$T-cells, with a decrease of the activation state of $\mathrm{CD}^{+}{ }^{+} \mathrm{T}$-cells during the second treatment cycle (Figure 3B). As expected, activated cells were primarily EM cells (Figure 3B dot plot, Additional file 1: Figure S2B). In accordance with these observations, the absolute count of EM $\mathrm{CD}^{+}{ }^{+} \mathrm{T}$-cells was increased during both cycles (Additional file 1: Figure S2C), whereas the absolute count of EM $\mathrm{CD}^{+}$T-cells only increased during the first cycle (Figure $3 \mathrm{C}$ ). $\mathrm{CD}^{+}$effector cell properties were not found to be altered by Selectikine treatment, as indicated by ex vivo assessment of intracellular expression of granzyme $\mathrm{B}$ and perforin (Figure 3D), and the production of IFN $\gamma$ and TNF $\alpha$ after a 4-h stimulation with PMA/ionomycin (Figure 3E). Finally, neopterin levels were increased, reflecting the overall activation of the cellular immune system (Additional file 1: Figure S2D).

\section{$\mathrm{CD} 4^{+}$Treg}

$\mathrm{CD}^{+}$Treg cells are inhibitory immune cells, characterized by high expression of Foxp3 and CD25. Besides CD25, Treg cells also express the remaining chains of the high-affinity IL-2 receptor, and are thus sensitive to IL-2 and Selectikine, similar to conventionally activated T-cells. As expected, the frequency of Treg cells was considerably increased after each treatment cycle, reaching a mean of approximately $25 \%$ of $\mathrm{CD}^{+}$T-cells (cycle 1, 24.5\% \pm 11.3 ; cycle 2, 23.8\% \pm 1.6 ) (Figure $4 \mathrm{~A}$ ). These Treg cells were $\mathrm{CD}^{+} \mathrm{CD}^{+}{ }^{+} \mathrm{CD}_{2} 5^{+}$Foxp $^{+}$and CD127 (Figure 4A, dot plot); CD127 expression being mainly expressed on subpopulations of $\mathrm{CD} 4^{+}$non-Treg cells and $\mathrm{CD}^{+} \mathrm{T}$-cells (Additional file 1: Figure S3A). Of note, a decrease in CD127 expression was observed on $\mathrm{CD}^{+}{ }^{+} \mathrm{T}$-cells but not on $\mathrm{CD} 8^{+} \mathrm{T}$-cells. The strong sensitivity to Selectikine of Treg cells was confirmed by absolute counts, with $20 \pm 60$ and $11 \pm 7$-fold increase in cycles 1 and 2 , respectively (day 8); while $\mathrm{CD}_{4}^{+}$nonTreg cells increased by $1.6 \pm 5$ and $1.5 \pm 0.5$-fold, respectively, similarly to $\mathrm{CD}^{+}$T-cells. This means that the $\mathrm{CD} 4^{+} / \mathrm{CD}^{+}{ }^{+}$ratio remained unchanged when excluding Treg cells (Figure 4B and Additional file 1: Figure S3B). Of note, a single injection of low-dose cyclophosphamide (group 2) did not affect their frequency (Additional file 1: Figure S3C). The inhibitory function of Treg cells at baseline (day 1) and on day 8 of the second treatment cycle was also measured in eight randomly selected 

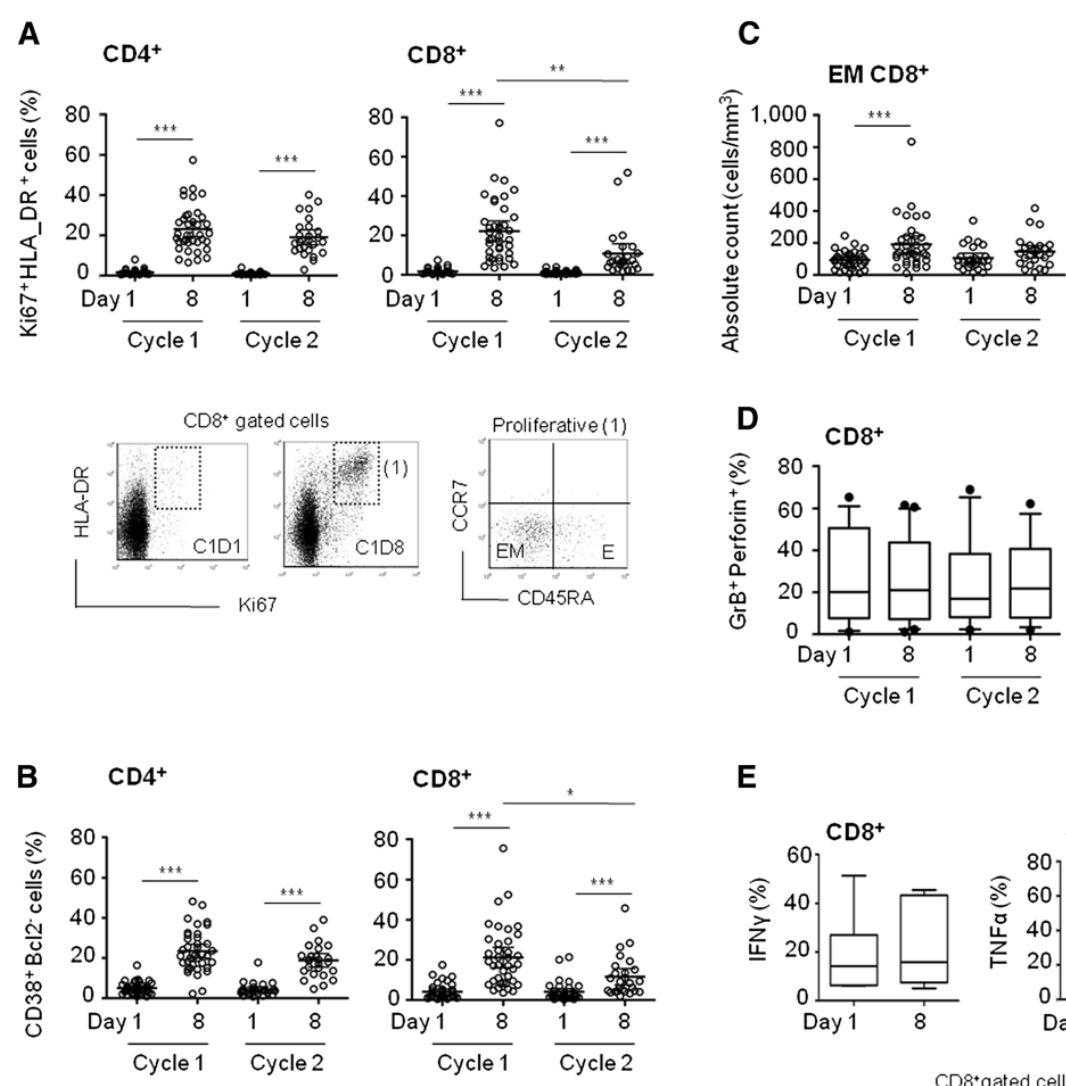

E
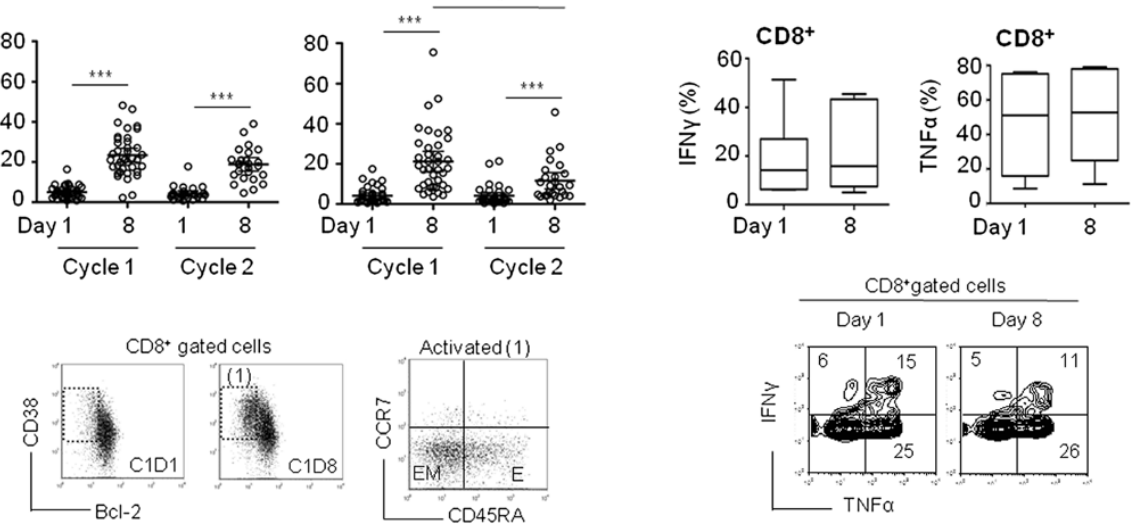

Figure 3 Functional analysis of $\mathrm{CD}^{+}$and $\mathrm{CD}^{+}{ }^{+} \mathrm{T}$-cells before and after treatment with Selectikine. (A) Frequencies (\%) of proliferative $\mathrm{CD}^{+}$and $\mathrm{CD} 8^{+}$T-cells (Ki67 ${ }^{+} \mathrm{HLA-DR^{+ }}$ ) on days 1 and 8 during the first and second treatment cycles. Dot plots represent HLA-DR versus Ki67 staining of $\mathrm{CD}^{+}$gated T-cells on days 1 and 8 during the first treatment cycle. The right dot plot shows expression of CCR7 and CD45RA of cells from gate (1), on day 8 of the first cycle. (B) Frequencies (\%) of activated cells (CD38 ${ }^{+} \mathrm{BCl} 2{ }^{-}$) within $\mathrm{CD} 4^{+}$and $\mathrm{CD} 8^{+} \mathrm{T}$-cells on days 1 and 8 during the first and second treatment cycle. Dot plots represent CD38 versus $\mathrm{Bc} / 2$ staining in $\mathrm{CD} 8^{+}$gated cells on days 1 and 8 during the first treatment cycle. The right dot plot represents CCR7 versus CD45RA repartition of activated CD8 ${ }^{+}$T-cells (1) on day 8 of the first cycle. (C) Absolute counts (cells $/ \mathrm{mm}^{3}$ ) of effector memory (EM) CD8 ${ }^{+}$T-cells (CCR7 ${ }^{-}$CD45RA') on days 1 and 8 during the first and second treatment cycles. Graphs show individual values of 39 treated patients. Bars represent geometric mean values with $95 \% \mathrm{Cl}$. (D) Frequency of $\mathrm{GrB}^{+}$perforin ${ }^{+}$cells in $\mathrm{CD}^{+}$gated cells on days 1 and 8 during the first and second treatment cycles. The box-and-whiskers graph shows geometric mean with $95 \% \mathrm{Cl}$. (E)

Expression of IFNy and TNFa (\%) in CD8 ${ }^{+}$T-cells on days 1 and 8 of the second cycle, after a 4-hour in vitro stimulation with PMA/ionomycin. Dot plot representation of IFNy versus TNFa staining in $\mathrm{CD}^{+}$gated T-cells after in vitro stimulation. Box-and-whiskers graphs show geometric mean with $95 \%$ Cl from 9 randomized patients treated with 0.075 to $0.9 \mathrm{mg} / \mathrm{kg}$ Selectikine alone. ${ }^{*} P<0.05,{ }^{* *} P \leq 0.01,{ }^{* *} P \leq 0.005$.

patients from group 1 (Additional file 1: Figure S3D). In five of these patients, Treg cells inhibited $\mathrm{CD} 4^{+}$T-cell proliferation between 60 and $100 \%$ (ratio 1:2) to a similar extent on days 1 and 8 . In the three remaining patients, Treg cells were not inhibitory on either day (Table 1). The increase of Treg cell frequency without changes of their inhibitory function may reflect early production of IL-10, as detected in sera on day 3 after the first dose of Selectikine (Figure 4C). Finally, analysis of Ki67 expression revealed that a mean of approximately
$50 \%$ of Treg cells were proliferating cells on day 8 (cycle 1 , $51.6 \% \pm 11.6$; cycle $2,46.7 \% \pm 15.8$ ) (Additional file 1 : Figure S3E).

\section{In situ analysis}

We further investigated whether lymphocytes accumulated in situ, by studying a post-treatment biopsy collected after the second cycle, from a patient with metastatic melanoma treated with $0.225 \mathrm{mg} / \mathrm{kg}$ of Selectikine and matched archival material collected shortly prior to start of Selectikine 


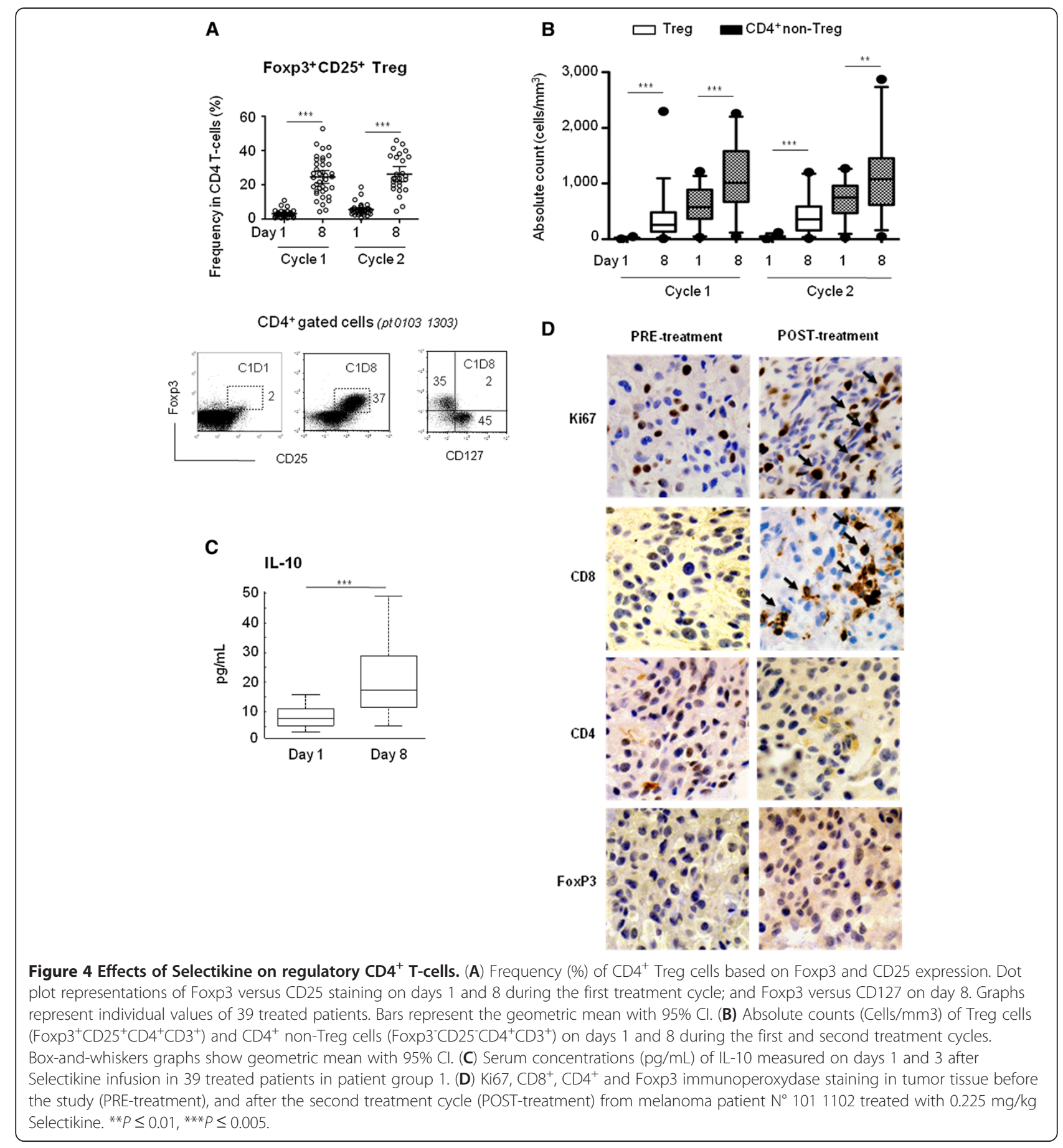

treatment. Interestingly immunohistochemistry staining revealed significantly increased expression of Ki67 by lymphocytes after Selectikine treatment compared with the pretreatment sample. Furthermore, there was an increased infiltration of $\mathrm{CD}^{+}{ }^{+}$-cells, while $\mathrm{CD}^{+}$and Foxp3 ${ }^{+}$Treg cells were unchanged (Figure 4D). Notably, post-therapy immune response in this patient was similar to other treated patients, with increased counts of $\mathrm{CD}^{+}, \mathrm{CD} 4^{+}$and
Treg cells, and strong activation and proliferation of T-cells (individual data not shown).

\section{Tumor-antigen specific $\mathrm{CD}^{+}{ }^{+} \mathrm{T}$-cells}

We investigated whether Selectikine treatment promoted responses of tumor-antigen specific $\mathrm{CD} 8^{+} \mathrm{T}$-cells. Of eight randomly selected HLA-A2 positive patients, $\mathrm{CD} 8^{+} \mathrm{T}$ cells were isolated at baseline and on day 8 after 
Table 1 Treg inhibition capacity

\begin{tabular}{lccc}
\hline \multicolumn{4}{c}{ Inhibition of CD4 } \\
\hline Dose & Patient & Droliferation by Tregs \\
\hline & & Dayhibition (\%) & Day 8 \\
0.075 & 1031301 & 99 & 88 \\
0.075 & 1031318 & 75 & 48 \\
0.075 & 1021213 & 68 & 49 \\
0.3 & 1031303 & 97 & 92 \\
0.3 & 1031309 & 0 & 0 \\
0.6 & 1031310 & 82 & 77 \\
0.6 & 1031314 & 0 & 2 \\
0.6 & 1011104 & 0 & 0
\end{tabular}

Capacity of inhibition (\%) of $\mathrm{CD}^{+} \mathrm{T}$-cell proliferation induced by $\mathrm{CD}^{+} / \mathrm{CD}^{2} 8^{+}$ stimulation by Treg cells, sorted on days 1 and 8 during the second treatment cycle. Samples from 8 randomized patients treated at $0.075,0.3$ and $0.6 \mathrm{mg} / \mathrm{kg}$ Selectikine alone were tested.

Selectikine infusion during the second cycle, and stimulated with a panel of peptides representing cancer-testis antigenic epitopes from the tumor antigens Melan-A, MAGE-A3, MAGE-A10, NY-ESO-1 and SSX-2. After one week of peptide stimulation, cells were isolated and stained with tetramers combined with intracellular staining for IFN $\gamma$ and TNF $\alpha$. Lymphocytes obtained from day 8 (second treatment cycle) did not show significant enrichment of tumor-antigen specific T-cells compared with those from day 1 (Additional file 1: Figure S4A). One patient showed strong activation of Melan-A specific Tcells at the baseline of the second cycle, but without a further increase on day 8 (Additional file 1: Figure S4B). Measurements of IFN $\gamma$ and TNF $\alpha$ production within tetramer positive $\mathrm{CD}^{+}$T-cells showed no functional enhancement after Selectikine treatment (Additional file 1: Figure S4C), which was similar to our findings for whole circulating $\mathrm{CD}^{+}$T-cells (Figure $3 \mathrm{E}$ ).

\section{Correlation with patient survival}

Preliminary evidence of clinical efficacy was investigated. No tumor responses were recorded, but prolonged disease stabilization in some of these heavily pre-treated patients observed. Median overall survival was 9.6 months [95\% CI 5.6-16.4] in group 1, and 7.0 months [95\% CI 4.3-23.2] in group 2. Previously reported [28-30], associations between patient survival and lymphocyte properties (as described in Figures 1 and 2), were further examined. Interestingly, high lymphocyte counts at baseline were significantly associated with longer survival (Figure 5A). Furthermore low levels of activated $\mathrm{CD}^{+}{ }^{+}$T-cells $(\mathrm{CD} 38+\mathrm{Bcl} 2-\%)$ at baseline were associated with longer patient survival (Figure 5B), while the absolute count was not (Figure 5C). Notably, the highest increase of $\mathrm{CD}^{+}{ }^{+} \mathrm{T}$-cell activation at day 8 was observed in patients who presented low activation levels before the start of treatment (Additional file 1:
Figure $\mathrm{S} 5 \mathrm{~A}$ ), and was thus independent of lymphocyte counts (Additional file 1: Figure S5B). Therefore, treatment induced T-cell activation appeared to occur preferentially in patients with low-level activation at baseline and seemed to be associated with improved clinical outcome in this small number of patients. Of note, Treg cells did not impact on overall survival (Additional file 1: Figure S5C).

\section{Discussion}

IL-2 therapy can be effective in the treatment of patients with metastatic renal cell carcinoma and metastatic melanoma [31]. Clinical responses to high-dose IL-2 therapy occur in $15 \%$ to $20 \%$ of patients. However, sideeffects are frequent and can be serious [32,33]. More targeted IL-2 therapies are necessary to improve safety and efficacy [34]. Several small phase II studies recorded some clinical responses with the administration of lower doses of IL-2 but no cases of long lasting responses were reported [35]. A randomized study comparing high- and low-dose IL-2 in 156 patients with metastatic renal cancer by Yang et al. [14], supported the finding that low-dose IL-2 regimens can cause the regression of advanced renal cell cancer. However, the higher dose of IL-2 appeared to produce greater biological activity, together with a higher clinical response rate.

The novel recombinant IL-2/anti-DNA fusion protein, Selectikine, was developed with the aim of maximizing immunomodulatory action and clinical efficacy at minimal vascular toxicity, despite treatment at optimal doses [36]. Our analysis of peripheral leukocytes showed a strong and transitory increase early after infusion of Selectikine. As expected, lymphocytes responded readily while the effects on monocytes were less pronounced, and no significant changes were observed to neutrophils (Figure 1). Strong increases in both percentages and absolute counts were observed for both $\mathrm{CD}^{+}$and $\mathrm{CD} 8^{+}$ T-cells (Figure 2), while only weak effects were found for NK cells (Additional file 1: Figure S1), confirming the selectivity of Selectikine for T-cells compared with native IL-2 and an immunocytokine comprising wild-type IL-2 [37]. Furthermore, major biological effects included a significant increase in the soluble factors sIL-2R, neopterin and IL-10 [38]. Recently, treatment with EMD 273063, a humanized anti-GD2 mAb fused to native IL2 , showed no significant effects on peripheral $\mathrm{CD}^{+}$and $\mathrm{CD}^{+}{ }^{+}$T-cells 10 days after infusion of the molecule [38]. Nevertheless, EMD 273063 administration resulted in increased levels of the soluble factors sIL-2R, neopterin and IL10, as reported in the present study.

Strong activation and proliferation of lymphocytes was observed, essentially of EM T-cells (Figure 3 and Additional file 1: Figure S2), even at the lowest dose $(0.075 \mathrm{mg} / \mathrm{kg})$ of Selectikine. In general, a dose effect on biological responses was not found. This was remarkable, since strong immune 


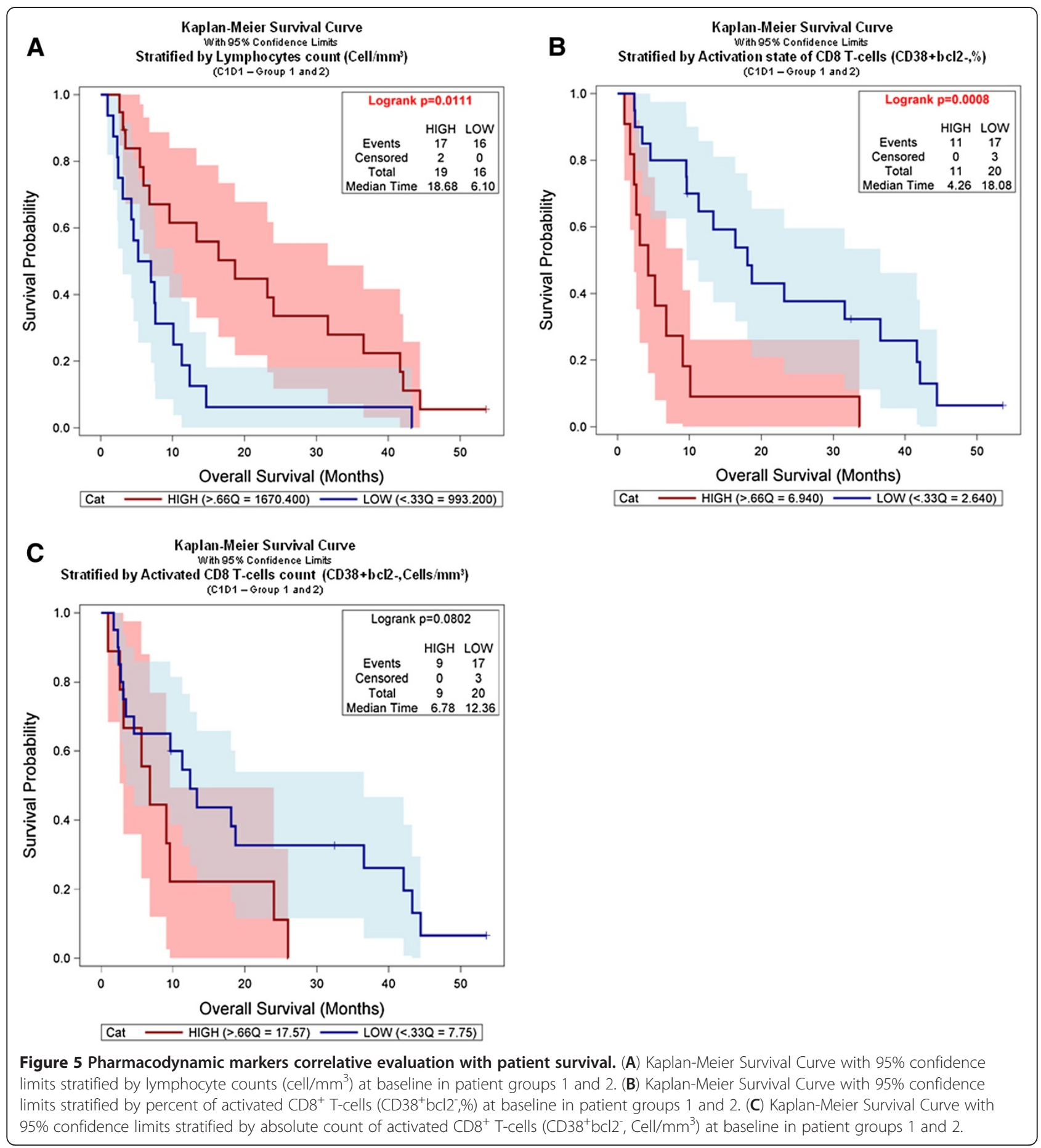

stimulation even at low doses of Selectikine, without major toxicity was demonstrated. In the field of IL-2 therapy, these biologic effects are considered as potentially beneficial. They are mostly observed at high doses with wild-type IL-2 and are thus associated with toxicity [39]. The absence of a dose effect in the present study should be interpreted with caution due to the heterogeneity of the patient population comprising different types of cancers with different pretreatment regimens. To reliably investigate a dose effect, a randomized study investigating different doses in a more homogeneous population would be necessary.

As expected, Treg cells responded actively, with increased frequencies and absolute counts after infusion of Selectikine (Figure 4A, B). However, their inhibitory capacities were unchanged (Table 1), based on the same cell ratio. The increase of Treg number is far more important than the 
increase of other T-cell populations, which could reflect a change in effector/regulatory T-cell ratio in vivo. Similarly to effector cells, Selectikine effects were transitory. Furthermore, increased Treg cell frequency appeared to be due to the proliferation of pre-existing Treg cells, as they expressed Ki67 (Additional file 1: Figure S3). The elevated levels of IL-10 may be a direct consequence of Treg cell sensitivity to the therapy (Figure 4C). Additional treatment with low dose cyclophosphamide prior to Selectikine infusion did not inhibit Treg cells (Additional file 1: Figure $\mathrm{S} 3 \mathrm{C}$ ), which is compatible with the majority of other studies [40]. The usefulness of cyclophosphamide for therapeutic inhibition of Treg cells remains questionable [41,42]. Importantly, in addition to Treg cells, the levels of $\mathrm{CD} 4^{+}$ effector T-cells were also increased after the infusion of Selectikine (Figure 4B). Furthermore, $\mathrm{CD}^{+}$effector T-cells were also activated and increased in numbers and frequencies. Thus, even if Treg cells were highly sensitive to Selectikine, T-cell activation was broad, with increased activity of both effector and regulatory T-cells, in contrast to recent studies of low dose IL-2 treatment demonstrating preferential and sustained activation of Treg cells $[43,44]$. The fact that Selectikine targets the tumor tissue through the binding of free DNA may result in a different T-cell activation in the tissue compared to periphery, which could perhaps also be the case for Treg cells as suggested by the analysis of the single post-therapy biopsy (Figure 4D). For this patient, the in situ analysis revealed different effects in the tumor compared to the periphery. This aspect should be addressed in future clinical trials.

Recently, Levin et al. have published the first results evaluating a new class of IL-2 named a superkine, which has been engineered to eliminate the functional requirement of CD25 expression [45]. In vitro and in vivo experiments revealed that the new IL-2 superkine induced superior expansion of cytotoxic T-cells compared to Treg cells, leading to improved antitumor responses and reduced pulmonary edema. Compared with the observations made with Selectikine, it will be interesting to evaluate both molecules in terms of immunological responses, toxicity and VLS when the IL-2 superkine reaches the clinic.

PBMC available from before and after the second treatment cycle were studied to investigate whether Selectikine treatment had detectable effects on tumor antigen-specific $\mathrm{CD}^{+}{ }^{+} \mathrm{T}$-cells. Several patients presented detectable levels of tumor-specific T-cells, and one patient developed a strong response. However, in most patients there was no increase in the frequency or the functionality of tumorspecific T-cells (Additional file 1: Figure S4). Even though many of these T-cells may have been induced by the treatment, in the absence of the assessment of pretreatment samples, this could not be formally addressed in this study. Unfortunately, it was also not possible to determine patient tumor antigen expression, which made it impossible to exclude those T-cells with specificities for non-expressed antigens (i.e. the majority) from the analysis. As a first-in-human study of Selectikine, at the time of the study design, these factors were not of high priority.

In cancer patients, tumor-infiltrating lymphocyte counts and localization are often independent prognostic factors for survival [46-50]. However, several studies including our own (Figure 5A) showed also that the counts of circulating lymphocytes correlated positively with survival [28-30]. Notably, in our study enhanced pre-activation of $\mathrm{CD} 8^{+} \mathrm{T}$-cells at baseline correlated with short survival (Figure 5B), while no correlation was observed when considering Treg cells (Additional file 1: Figure S5C). However, these are preliminary observations since the phase I study design and the low patient number do not allow for definitive conclusions on clinical outcome. Larger studies are required to address these questions, and to test whether low-level T-cell activation at baseline, and strong therapy induced $\mathrm{T}$-cell activation are predictive for favourable clinical outcome.

\section{Conclusion}

This first-in-human trial with Selectikine, a novel immunocytokine IL-2/anti-DNA fusion protein, confirms its selective biologic activity. Larger studies are now required to confirm our findings, and to determine potential clinical benefits. Finally, further analyses of post-treatment biopsies will provide more detailed insights into the biological effects of the dual targeting (IL-2R/DNA) by Selectikine.

\section{Additional file}

Additional file 1: Materials and methods.

\section{Abbreviations}

DAB: Diaminobenzidine; EM: Effector memory; FACS: Fluorescence-activated cell sorting; IL-2: Interleukin-2; IL-2R: Interleukin-2 receptors; iv: Intravenous; mAb: Monoclonal antibody; PD: Pharmacodynamic.

\section{Competing interests}

$J \mathrm{~L}, \mathrm{SO}, \mathrm{BL}$ and SQ are currently employees of Merck KGaA and UG was an employee of Merck KGaA from 2005-2009, was a consultant for Merck KGaA from 2009-2011, and has received funds for travel from Merck KGaA. All other authors report no conflicts of interest.

\section{Authors' contributions}

$J \mathrm{~L}$ participated in the design, analysis and data interpretation of immunomonitoring and wrote the manuscript draft; CT, MV participated in FACs analysis; MJ performed in vitro functional tests and tetramer analysis; SO and BL performed analysis of soluble factors; SO participated in statistical analysis; SQ, RS were involved in study design; BL and UGV were medical leaders in the project; RS was involved in patient recruitment. All authors participated in critical review of the manuscript and final approval to submit.

\section{Acknowledgements}

The authors thank the patients for collaboration, and we acknowledge Julia Rengier from CHUV (Lausanne, Switzerland) for study coordination and data management; Petra Pollert and Heike Pausch (Merck KGaA, Darmstadt, Germany), for operational study management and ICON Clinical Research 
(Dublin, Ireland) for sample logistics and analyses of neopterin and sIL-2. The authors also thank Anne Papaioannou for flow cytometry analysis of group 1. Dr Jim Heighway of Cancer Communications and Consultancy Ltd, Knutsford, UK provided editorial assistance, which was funded by Merck KGaA, Darmstadt, Germany. Funding for this work was provided by Merck KGaA, Darmstadt, Germany $(J L)$ and supported by the Ludwig Institute for Cancer Research, and the Cancer Vaccine Collaborative (USA) (DES).

\section{Author details}

${ }^{1}$ Division of Experimental Oncology, Multidisciplinary Oncology Center, Centre Hospitalier Universitaire Vaudois, Lausanne, Switzerland. ${ }^{2}$ Kantonsspital, St. Gallen, Switzerland. ${ }^{3}$ Global Clinical Development Unit-Oncology, Merck KGaA, Frankfurter Str. 250, D-64293, Darmstadt, Germany. ${ }^{4}$ Oncology Institute of Southern Switzerland, Bellinzona, Switzerland. ${ }^{5}$ University of Mainz, Mainz, Germany. ${ }^{6}$ Multidisciplinary Oncology Center, Centre Hospitalier Universitaire Vaudois and University of Lausanne, Lausanne, Switzerland. ${ }^{7}$ Clinical Tumor Biology \& Immunotherapy Unit, Ludwig Center of the University of Lausanne, Lausanne, Switzerland. ${ }^{8}$ IRBA antenne CRSSA, La Tonche, France. ${ }^{9}$ CureVac GmbH, Frankfurt, Germany.

Received: 22 August 2012 Accepted: 21 December 2012 Published: 7 January 2013

\section{References}

1. Dunn GP, Bruce AT, Ikeda H, Old L, Schreiber RD: Cancer immunoediting: from immunosurveillance to tumor escape. Nat Immunol 2002, 3:991-998.

2. Gabrilovich DI, Nagaraj S: Myeloid-derived suppressor cells as regulators of the immune system. Nat Rev Immunol 2009, 9:162-174.

3. Pardoll D: Does the immune system see tumors as foreign or self? Annu Rev Immunol 2003, 21:807-839.

4. Boyman O, Purton JF, Surh CD, Sprent J: Cytokines and T-cell homeostasis. Curr Opin Immunol 2007, 19:320-326.

5. Malek TR, Yu A, Zhu L, Matsutani T, Adeegbe D, Bayer AL: IL-2 family of cytokines in $\mathrm{T}$ regulatory cell development and homeostasis. J Clin Immunol 2008, 28:635-639.

6. Malek TR: The biology of interleukin-2. Annu Rev Immunol 2008, 26:453-479.

7. Sakaguchi S, Sakaguchi N, Asano M, Itoh M, Toda M: Immunologic selftolerance maintained by activated $\mathrm{T}$ cells expressing $\mathrm{IL}-2$ receptor alpha-chains (CD25). Breakdown of a single mechanism of self-tolerance causes various autoimmune diseases. J Immunol 1995, 155:1151-1164

8. Smith FO, Downey SG, Klapper JA, Yang JC, Sherry RM, Royal RE, Kammula US, Hughes MS, Restifo NP, Levy CL, et al: Treatment of metastatic melanoma using interleukin-2 alone or in conjunction with vaccines. Clin Cancer Res 2008, 14:5610-5618.

9. Klapper JA, Downey SG, Smith FO, Yang JC, Hughes MS, Kammula US, Sherry RM, Royal RE, Steinberg SM, Rosenberg S: High-dose interleukin-2 for the treatment of metastatic renal cell carcinoma: a retrospective analysis of response and survival in patients treated in the surgery branch at the National Cancer Institute between 1986 and 2006. Cancer 2008, 113:293-301.

10. Epstein AL, Mizokami MM, Li J, Hu P, Khawli LA: Identification of a protein fragment of interleukin 2 responsible for vasopermeability. J Nat Cancer Institute 2003, 95:741-749.

11. Nakagawa K, Miller FN, Sims DE, Lentsch AB, Miyazaki M, Edwards MJ: Mechanisms of interleukin-2-induced hepatic toxicity. Cancer Res 1996, 56:507-510.

12. Krieg C, Letourneau S, Pantaleo G, Boyman O: Improved IL-2 immunotherapy by selective stimulation of IL-2 receptors on lymphocytes and endothelial cells. Proc Natl Acad Sci U S A 2010, 107:11906-11911.

13. McDermott DF, Atkins MB: Application of IL-2 and other cytokines in renal cancer. Expert Opin Biol Ther 2004, 4:455-468.

14. Satoh T, Saika T, Ebara S, Kusaka N, Timme TL, Yang G, Wang J, Mouraviev V, Cao G, el Fattah MA, Thompson TC: Macrophages transduced with an adenoviral vector expressing interleukin 12 suppress tumor growth and metastasis in a preclinical metastatic prostate cancer model. Cancer Res 2003, 63:7853-7860.

15. Baluna R, Rizo J, Gordon BE, Ghetie V, Vitetta ES: Evidence for a structural motif in toxins and interleukin-2 that may be responsible for binding to endothelial cells and initiating vascular leak syndrome. Proc Natl Acad Sci U S A 1999, 96:3957-3962.

16. Shanafelt $A B$, Lin $Y$, Shanafelt $M C$, Forte $C P$, Dubois-Stringfellow $N$, Carter $C$, Gibbons JA, Cheng SL, Delaria KA, Fleischer R, et al: A T-cell-selective interleukin 2 mutein exhibits potent antitumor activity and is well tolerated in vivo. Nat Biotechnol 2000, 18:1197-1202.

17. Gillies SD, Lan Y, Hettmann T, Brunkhorst B, Sun Y, Mueller SO, Lo KM: A low-toxicity IL-2-based immunocytokine retains antitumor activity despite its high degree of IL-2 receptor selectivity. Clin Cancer Res 2011, 17:3673-3685.

18. de Bruin EC, Medema JP: Apoptosis and non-apoptotic deaths in cancer development and treatment response. Cancer Treat Rev 2008, 34:737-749.

19. Proskuryakov SY, Gabai VL: Mechanisms of tumor cell necrosis. Curr Pharm Des 2010, 16:56-68.

20. Li L, Okino T, Sugie T, Yamasaki S, Ichinose Y, Kanaoka S, Kan N, Imamura M: Cyclophosphamide given after active specific immunization augments antitumor immunity by modulation of Th1 commitment of CD4+ T cells. J Surg Oncol 1998, 67:221-227.

21. Kottke T, Thompson J, Diaz RM, Pulido J, Willmon C, Coffey M, Selby P, Melcher A, Harrington K, Vile RG: Improved systemic delivery of oncolytic reovirus to established tumors using preconditioning with cyclophosphamide-mediated Treg modulation and interleukin-2. Clin Cancer Res 2009, 15:561-569.

22. Ghiringhelli F, Menard C, Puig PE, Ladoire S, Roux S, Martin F, Solary E, Le Cesne A, Zitvogel L, Chauffert B: Metronomic cyclophosphamide regimen selectively depletes CD4 + CD25+ regulatory $T$ cells and restores $T$ and NK effector functions in end stage cancer patients. Cancer Immunol Immunother 2007, 56:641-648.

23. Bracci L, Moschella F, Sestili P, La Sorsa V, Valentini M, Canini I, Baccarini S, Maccari S, Ramoni C, Belardelli F, Proietti E: Cyclophosphamide enhances the antitumor efficacy of adoptively transferred immune cells through the induction of cytokine expression, B-cell and T-cell homeostatic proliferation, and specific tumor infiltration. Clin Cancer Res 2007, 13:644-653.

24. Gillessen S, Gnad-Vogt US, Gallerani E, Beck J, Sessa C, Omlin A, Mattiacci MR, Liedert B, Kramer D, Laurent J, et al: A phase I dose-escalation study of the immunocytokine EMD 521873 (Selectikine) in patients with advanced solid tumours. Eur J Cancer 2012, 49:35-44.

25. Grayson JM, Zajac AJ, Altman JD, Ahmed R: Cutting edge: increased expression of $\mathrm{BCl}-2$ in antigen-specific memory CD8+ T cells. $\mathrm{J}$ Immunol 2000, 164:3950-3954.

26. Laurent J, Speiser DE, Appay V, Touvrey C, Vicari M, Papaioannou A, Canellini G, Rimoldi D, Rufer N, Romero P, et al: Impact of 3 different short-term chemotherapy regimens on lymphocyte-depletion and reconstitution in melanoma patients. J Immunother 2010, 33:723-734.

27. Natarajan V, Lempicki RA, Sereti I, Badralmaa Y, Adelsberger JW, Metcalf JA, Prieto DA, Stevens R, Baseler MW, Kovacs JA, Lane HC: Increased peripheral expansion of naive CD4+ T cells in vivo after IL-2 treatment of patients with HIV infection. Proc Natl Acad Sci U S A 2002, 99:10712-10717.

28. Aliustaoglu M, Bilici A, Ustaalioglu BB, Konya V, Gucun M, Seker M, Gumus $M$ : The effect of peripheral blood values on prognosis of patients with locally advanced gastric cancer before treatment. Med Oncol 2010, 27:1060-1065

29. Fogar P, Sperti C, Basso D, Sanzari MC, Greco E, Davoli C, Navaglia F, Zambon CF, Pasquali $C$, Venza $E$, et al: Decreased total lymphocyte counts in pancreatic cancer: an index of adverse outcome. Pancreas 2006, 32:22-28.

30. Qiu H, Xiao-Jun W, Zhi-Wei Z, Gong C, Guo-Qiang W, Li-Yi Z, Yuan-Fang L, Rajiv-Prasad K: The prognostic significance of peripheral T-lymphocyte subsets and natural killer cells in patients with colorectal cancer. Hepatogastroenterology 2009, 56:1310-1315.

31. Dutcher J: Current status of interleukin-2 therapy for metastatic renal cell carcinoma and metastatic melanoma. Oncology (Williston Park) 2002, 16:4-10.

32. Fyfe G, Fisher RI, Rosenberg SA, Sznol M, Parkinson DR, Louie AC: Results of treatment of 255 patients with metastatic renal cell carcinoma who received high-dose recombinant interleukin-2 therapy. J Clin Oncol 1995, 13:688-696.

33. Rosenberg SA, Yang JC, White DE, Steinberg SM: Durability of complete responses in patients with metastatic cancer treated with high-dose interleukin-2: identification of the antigens mediating response. Ann Surg 1998, 228:307-319. 
34. Schwartz RN, Stover L, Dutcher J: Managing toxicities of high-dose interleukin-2. Oncology (Williston Park) 2002, 16:11-20.

35. Lopez Hanninen E, Kirchner H, Atzpodien J: Interleukin-2 based home therapy of metastatic renal cell carcinoma: risks and benefits in 215 consecutive single institution patients. J Urol 1996, 155:19-25.

36. Hu P, Mizokami M, Ruoff G, Khawli LA, Epstein AL: Generation of lowtoxicity interleukin-2 fusion proteins devoid of vasopermeability activity. Blood 2003, 101:4853-4861.

37. Alter G, Malenfant JM, Altfeld M: CD107a as a functional marker for the identification of natural killer cell activity. I Immunol Methods 2004, 294:15-22.

38. Ribas A, Kirkwood JM, Atkins MB, Whiteside TL, Gooding W, Kovar A, Gillies SD, Kashala O, Morse MA: Phase I/II open-label study of the biologic effects of the interleukin-2 immunocytokine EMD 273063 (hu14.18-IL2) in patients with metastatic malignant melanoma. J Trans/ Med 2009, 7:68

39. Fehniger TA, Cooper MA, Caligiuri MA: Interleukin-2 and interleukin-15: immunotherapy for cancer. Cytokine Growth Factor Rev 2002, 13:169-183.

40. Boyman O, Sprent J: The role of interleukin-2 during homeostasis and activation of the immune system. Nat Rev Immunol 2012, 12:180-190.

41. Audia S, Nicolas A, Cathelin D, Larmonier N, Ferrand C, Foucher P, Fanton A, Bergoin E, Maynadie M, Arnould L, et al: Increase of CD4+ CD25+ regulatory $T$ cells in the peripheral blood of patients with metastatic carcinoma: a Phase I clinical trial using cyclophosphamide and immunotherapy to eliminate CD4+ CD25+ T lymphocytes. Clin Exp Immunol 2007, 150:523-530.

42. Cao Y, Zhao J, Yang Z, Cai Z, Zhang B, Zhou Y, Shen GX, Chen X, Li S, Huang B: CD4 + FOXP3+ regulatory T cell depletion by low-dose cyclophosphamide prevents recurrence in patients with large condylomata acuminata after laser therapy. Clin Immunol 2010, 136:21-29.

43. Koreth J, Matsuoka K, Kim HT, McDonough SM, Bindra B, Alyea EP 3rd, Armand P, Cutler C, Ho VT, Treister NS, et al: Interleukin-2 and regulatory $T$ cells in graft-versus-host disease. N Engl J Med 2011, 365:2055-2066.

44. Saadoun D, Rosenzwajg M, Joly F, Six A, Carrat F, Thibault V, Sene D, Cacoub P, Klatzmann D: Regulatory T-cell responses to low-dose interleukin-2 in HCV-induced vasculitis. N Engl J Med 2011, 365:2067-2077.

45. Levin AM, Bates DL, Ring AM, Krieg C, Lin JT, Su L, Moraga I, Raeber ME, Bowman GR, Novick P, et al: Exploiting a natural conformational switch to engineer an interleukin-2 'superkine'. Nature 2012, 484:529-533.

46. Deschoolmeester V, Baay M, Van Marck E, Weyler J, Vermeulen P, Lardon F, Vermorken JB: Tumor infiltrating lymphocytes: an intriguing player in the survival of colorectal cancer patients. BMC Immunol 2010, 11:19.

47. Chung SK, Maiti KK, Lee WS: Recent advances in cell-penetrating, nonpeptide molecular carriers. Int J Pharm 2008, 354:16-22.

48. Nosho K, Baba Y, Tanaka N, Shima K, Hayashi M, Meyerhardt JA, Giovannucci E, Dranoff G, Fuchs CS, Ogino S: Tumour-infiltrating T-cell subsets, molecular changes in colorectal cancer, and prognosis: cohort study and literature review. J Pathol 2010, 222:350-366.

49. Rauser S, Langer R, Tschernitz S, Gais P, Jutting U, Feith M, Hofler H, Walch A: High number of CD45RO + tumor infiltrating lymphocytes is an independent prognostic factor in non-metastasized (stage I-IIA) esophageal adenocarcinoma. BMC Cancer 2010, 10:608.

50. Stumpf M, Hasenburg A, Riener MO, Jutting U, Wang C, Shen Y, OrlowskaVolk M, Fisch P, Wang Z, Gitsch G, et al: Intraepithelial CD8-positive T lymphocytes predict survival for patients with serous stage III ovarian carcinomas: relevance of clonal selection of T lymphocytes. Br J Cancer 2009, 101:1513-1521.

doi:10.1186/1479-5876-11-5

Cite this article as: Laurent et al:: T-cell activation by treatment of cancer patients with EMD 521873 (Selectikine), an IL-2/anti-DNA fusion protein. Journal of Translational Medicine 2013 11:5.

\section{Submit your next manuscript to BioMed Central and take full advantage of:}

- Convenient online submission

- Thorough peer review

- No space constraints or color figure charges

- Immediate publication on acceptance

- Inclusion in PubMed, CAS, Scopus and Google Scholar

- Research which is freely available for redistribution

Submit your manuscript at www.biomedcentral.com/submit
C Biomed Central 